\title{
Sustainable living and building indicators in Old Ağırnas and their interpretations for new practice and research
}

\author{
B. Mizrak \& S. Erkenez \\ Department of Architecture, Yildiz Technical University, Turkey
}

\begin{abstract}
There is usually a gap between the works of vernacular architecture and the current building practices in small towns in Anatolia. This gap grows each day, changes the living habits and culture, and damages the continuity of the development. This paper attempts to address this disconnection from the eco-cultural logic perspective and analyses a small town called Ağırnas in Central Anatolia Region in Turkey, in which the first settlements were assumed to be founded in the $1^{\text {st }}$ century AD. It highlights the unique ecological, socio-cultural and architectural values of the town and provides a glance to its current practices. To do so, literature has been reviewed and interviews have been conducted with local people, local authorities, and the architect Cengiz Bektas, who is an Aga Khan and Mimar Sinan Award winner. In addition to the exploration of the discontinuity of values, as an ultimate output, the paper proposes two frameworks, which provide sustainability roadmaps for current building practices and for further research and study in fields other than building.

Keywords: sustainable living culture, sustainable building culture, Turkish vernacular architecture, sustainability indicators, sustainability interpretations, Ağırnas, Kayseri, Turkey.
\end{abstract}

\section{Introduction}

The cultural diversity, the resources, and the economy of a society creates a system in itself, which is independent from the external forces. And, every society is a part of the whole and it is meaningful within its own network of relationships (Ciravoğlu [1]). The key of sustainable architecture is the necessity to assess the design process from a holistic perspective. Sustainable architecture is not only 
about the use of environmentally friendly materials. To ensure a real sense of achievement, consideration of cultural, social and economic sustainability is as important as the consideration of environmental sustainability (Gould [2]). This study, departing from the assumption that architecture build lifestyles, emphasizes the necessity of an architecture, which is handled with the social, economical and environmental aspects. Ağırnas is a town of Kayseri in Central Anatolia Region in Turkey. It's also the place, where the great Ottoman Architect Sinan was born and lived for approximately 21 years. "I wouldn't be me, if Ağırnas didn't exist. My village trained me." are his own sentences. Ağırnas has existed for centuries with its underground and aboveground settlements and has achieved to come to the present day in spite of all obstacles. Depending upon the social transformations in Turkey, a huge decrease in its population has been seen and its works of architecture have lost their identity and been corrupted in time. These problems belonging to Ağırnas are the starting point of this study. Through the eco-cultural design approach, it is tried to be underlined that there is a requisiteness of examining the local values and, adopting or developing the logic behind their solutions in order to have an architecture in harmony with nature. So firstly, environmental, socio-cultural, and architectural values of old Ağırnas are analysed in the study. Then, the discontinuity in these values is explained and, the current situation over these values is described. And lastly, as an ultimate output, two frameworks are proposed both for further research and practice.

\section{The eco-cultural approach: Cengiz Bektas and methodology}

The eco-cultural approach, which is the conceptual framework of this study, emphasizes a fundamental reorientation of values to establish a connection with environmental and cultural concerns. The approach argues that it should be aimed to conserve the richness and diversity of life and human cultural diversity should be a part of it (Naess [3]). This requires a further step from ecologically sustainable development to long-term 'ecosophical' development. The approach stresses decentralization and it concerned with characteristics of regions or bioregions, which are conceived as the basic geographical unit of a small-scale ecological society. Sustainability means living within the constraints and posibilities imposed by these characteristics, and as a design strategy, bioregionalism gets inspiration from vernacular building approaches. The eco culturel logic emphasizes both the preservation and conservation of the variety of built cultural prototypes. It should be combined with a concern for cultural continuity through the transformation and reuse of tradinational construction techniques, building typologies, and settlement patterns (Guy and Farmer [4]). In Bektas's approach, architectural projects are not restricted only with technical concerns; but the lifestyles, future scenarios, and cultural backgrounds are all perceived as a part of the projects (Güzer [5]). Bektaş expresses this approach in his book titled 'The Art of Indigenous Construction'. $\mathrm{He}$ researches on design parameters like place selection, orientation, memory, space organization, local techniques and metarials, and resource utilization in the book over twenty settelments. As a result of his experiences, he comes up with 
princples in respect of nature, respect to humankind, consciousness of cultural richness, sparingness, flexibility, realism, responsible material and construction technique selection. As it is seen, these criteria do not only deal with physical form but also concern about the human dimension of the projects (Bektaş [6]). In order to collect data for the study, observations are made in Ağirnas and the surrounding towns. Environmental, socio-cultural, and economic structures are researched through interviews with local authorities and people who live in there. The gathered information is supported by literature study and vice versa. After the data collection phase, sustainability roadmaps are proposed for further research and practice.

\section{Ağirnas in the past}

\subsection{Environmental values}

Ağırnas has a continental climate, in which summers are hot and dry, and winters are cold and snowy. In the region, through the spread of volcanic material from inactive Volcano Mount Erciyes, tuff and soft rocks became the main construction materials. The old settlement was located on the valley slope in order to be close to the spring, which arrives to Ağırnas from the top of the valley. The soil is not fertile in Ağırnas. So, the seeds have been generally produced in buildings specialized for this function.

\subsection{Socio-cultural values}

Socio-cultural values are important factors shaping the space and the environment. The community's cultural beliefs, social practices within the socio-cultural context lead to the formation of life patterns in houses and around; they create the architectural form. For instance, collective working 'imece' is an important praxis in Anatolian culture. Through this tradition people work together without any written rule or payment. This cooperation system establishes bonds of love and respect between people and improves human interaction. This commitment made possible the non-Muslims and Muslims to live together in peace and generated a unique architecture as a result of the cultural mosaic. It still exists in small towns in Anatolia, but there isn't as much work as there was in the past, which has the power to reshape the environments. Patriarchal structure was another important character of Anatolian culture. It's still a part of the culture in this region, but it's not as dominant as it was in the past. Till the 50s, grandparents, children, and grandchildren all lived together in the same house. And this has affected the domestic architecture. The environmental characteristics also affected the main sources of income in the town. The tuff and soft volcanic rocks made the stone masonry an important workmanship. Stockbreeding was another important part of the everyday life in Ağırnas. 


\subsection{Architectural values}

\subsubsection{Settlement to the land}

The soft and easy to be carved rocks of the region and the necessity for protection and defense in dwellings in 1st Century AD have resulted in the establishment of underground settlements. It is assumed that those underground settlements continue for kilometers and there is a physical connection with the other underground settlements typical in Central Anatolia, which points out a huge civilization. It's evidently seen that today's protected and preserved examples of vernacular architecture from $16^{\text {th }}$ Century in Ağırnas have been constructed on top of the traces of those underground settlements. As a result of these, the site plan of Ağırnas has obtained an organic character. Two-storey stone houses behind courtyard-garden walls costituted the organic settlement pattern and the organic street pattern is shaped from semi-public to public order. Although the houses don't follow a strict rule for their orientations, the hillside facing to the southwest make houses take advantage of the sunlight during the daytime.

\subsubsection{Exterior walls of buildings}

When examining the shells of the buildings in Ağırnas, it's necessary to start with the underground constructions, because they offer more ecologically sustainable and efficient solutions than the overground ones do. According to Mustafa Özçelik, who is an employee of the Municipality of Ağırnas, those underground constructions continue 20-25 meters below ground and this corresponds to roughly 4-5 storeys, whose floor height is around 4 meters. As it is observed in the underground caverns in the town, there are the 1-meter-thick rubble stone wallsdividing the spaces. Thick walls and the soil surrounding those spaces inevitably resulted in houses cool in summers and warm in winters. While the thickness of exterior walls in ground floors are also around 1 meter, the wall thickness in the upper floors decreases to 20 centimeters. This difference comes from the different construction techniques and materials frequently used at the times that they were built. The first and second floors of the houses were constructed in 1920s and -30s (Okyay [7]). The masonry work in those years made possible these $20-\mathrm{cm}$-thick exterior walls and larger openings, and this lightened the structure. However, this creates warmer interiors in summer and colder interiors in winter. The floors and beams were from juniper. In short, the existence of soft rocks and workable stones brought into existence the houses with very law embodied energy. Also, the thick walls and underground settlements kept the indoor air temperature in thermal comfort interval.

\subsubsection{Openings}

The openings differ from each other according to their function and their time that have been constructed. The caverns have long and narrow flues, which provides natural ventilation and also some light inside. On top of the cavern in the ground floor, there are $30 \mathrm{~cm} \times 40 \mathrm{~cm}$ windows and one-person-wide doors. In the first and second floors, the height of windows gets to 1 meter. The windows in ground floors have only iron bars in their front without any frame, the windows of first and second floors have either iron or wooden frames and they are usually double 
windows. The windows facing to the street have iron frames and the windows facing to the courtyard have wooden frames because of security precautions. And, there isn't any sunshading element observed.

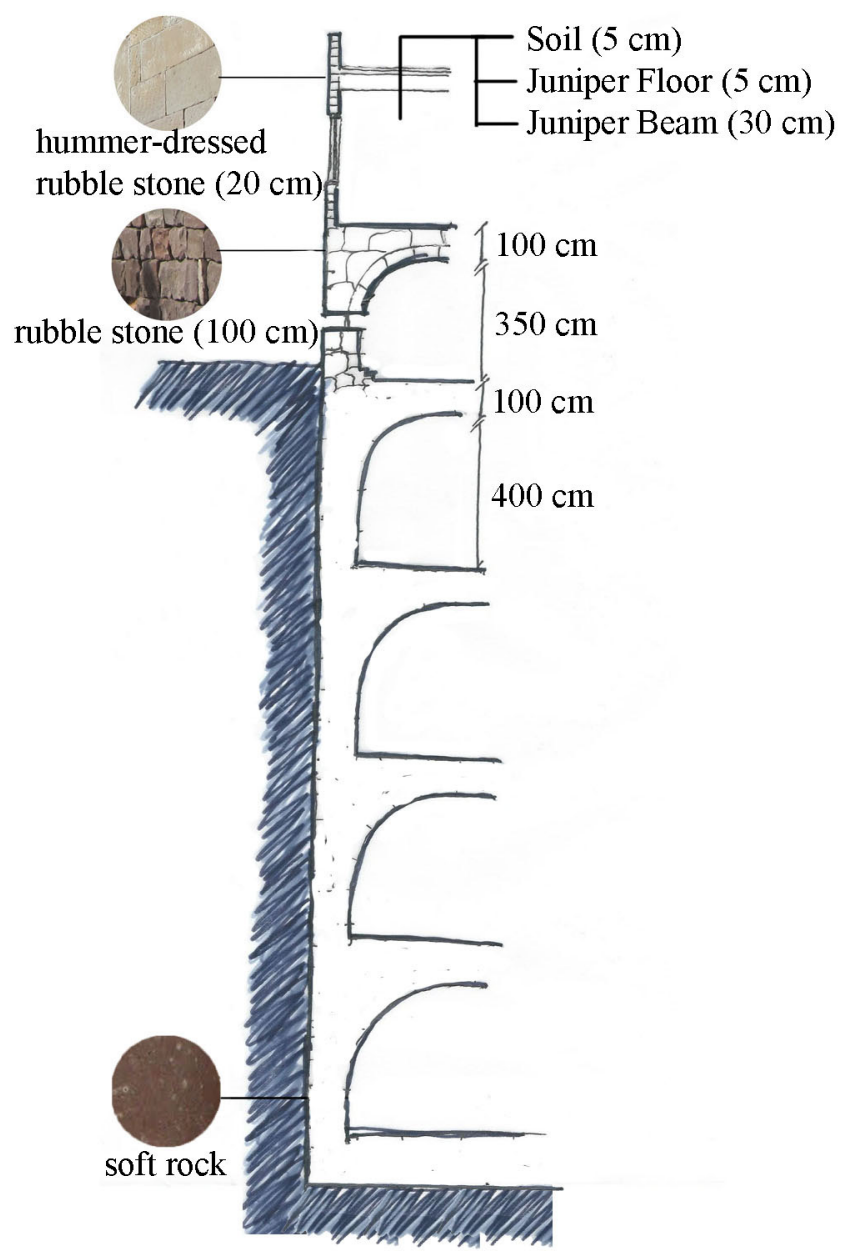

Figure 1: Detail section of a typical vernacular house in Ağırnas.

\subsubsection{Passive climatization: heat sources}

The place of the heat sources is the base of passive climatization in vernacular architecture in the region and in Ağırnas. In pre-republican period, when only the caverns and the single-storey houses existed, it was cooked both in winters and in summers in the middle of the main living area of the house, namely the house of the floor furnace (tandır evi). The elderlies of Ağırnas, with whom long conversations have been made, have declared that cooking in the floor furnace in the main living area was never disturbing in summers, because the indoor climate 
was quite cool. And as it is easily guessed, the furnace provided a much warmer interior in winters. When it is called heat source, it refers not only to the cooking fire but also to the cattle generally in the whole Anatolia. In pre-republican period in Ağırnas, when the main living area was in the ground floor, people stayed together with their animals in the house of floor furnace at winter nights. When the cooking fire was extinguished, it was set up a metal structure called "iskembi" around the floor furnace. Then, a blanket has been put on top of this metal structure and people lie down underneath. However, the main living activities in houses switched to the first and second floors in the 30s and this led to the loss of these authentic and unique solutions. The ground floors and basements started to be used for storage. The main living area and the floor furnace in it have lost their importance. The cooking activity started to take place in the courtyard in a place called 'tandir sekisi', which is $2-3 \mathrm{~m}^{2}$ in size.
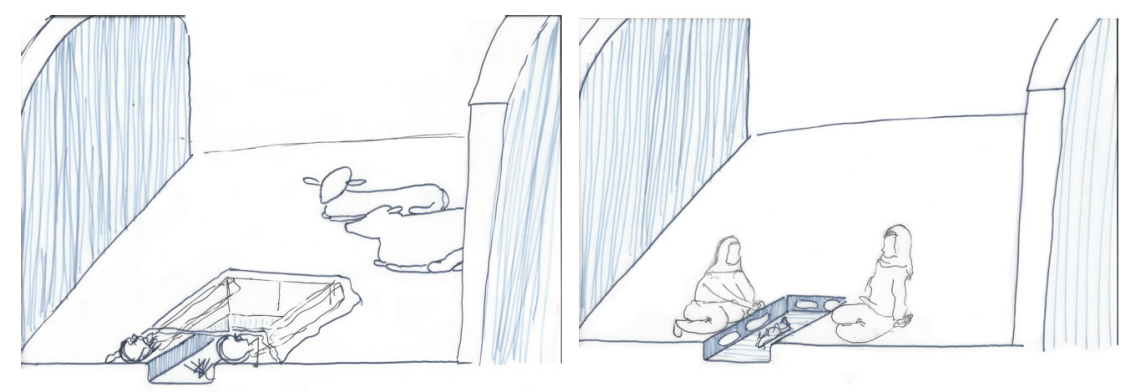

Figure 2: Living culture analysis in winter-nighttime and winter/summerdaytime.

Okyay declares in her thesis that the move of the furnace's place to the courtyard contributed to the thermal comfort inside the house in summertime (Okyay [7]). And this is comprehensible, because the first and second floors having $20 \mathrm{~cm}$-thick-exterior walls were not able to tolerate the heat of a furnace anymore like the 1-m-thick walls did formerly.

\subsubsection{Water sources and water use}

Ağırnas suffered from water shortages through its history. There are three monumental fountains, to which water was brought from the spring ten kilometers away by special channels. As a resident of Ağirnas stated, the spring water of Hacetpinari was not used in Ağırnas and sent to Kayseri till $18^{\text {th }}$ Century. It is observed that the snow water is collected in the rocks with a hollow under the gargoyles. In addition to the water sources, information is also gathered about the water use in the town. While the washing and cleaning activites took place around the fountains, the water used in the house has brought from the fountains with a copper vessel typical in the region. And, it was used in the house in a sanitary ware called 'cagi tasi' wich functions as a washbasin and is located in courtyards, in living rooms (sofa), or in the rooms. 


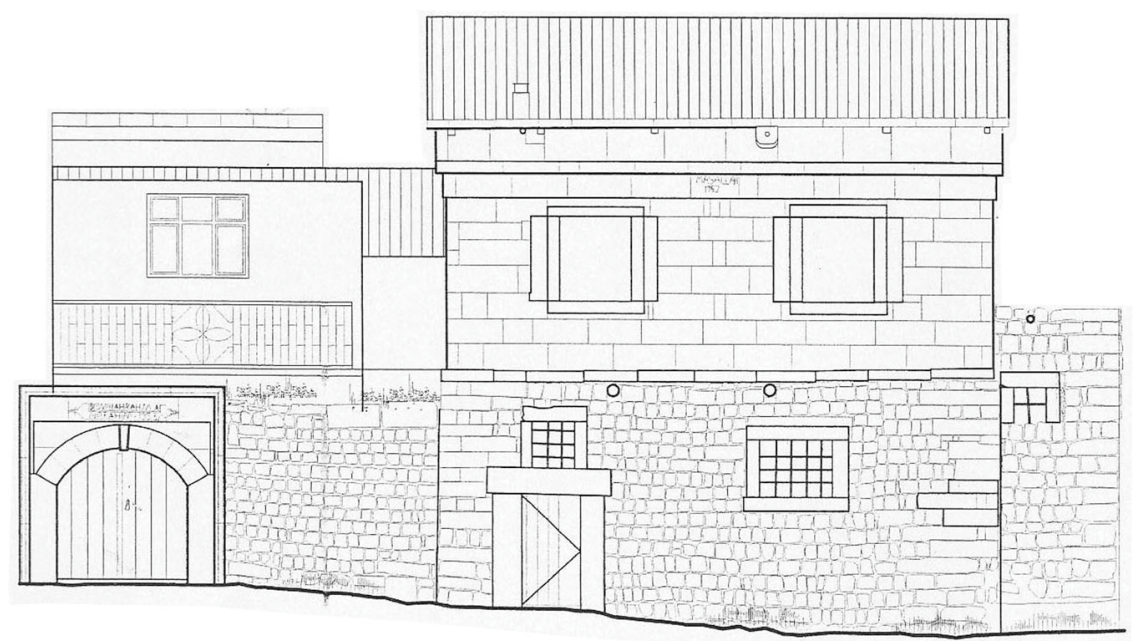

Figure 3: Elevation of Bahri Ozkan house.

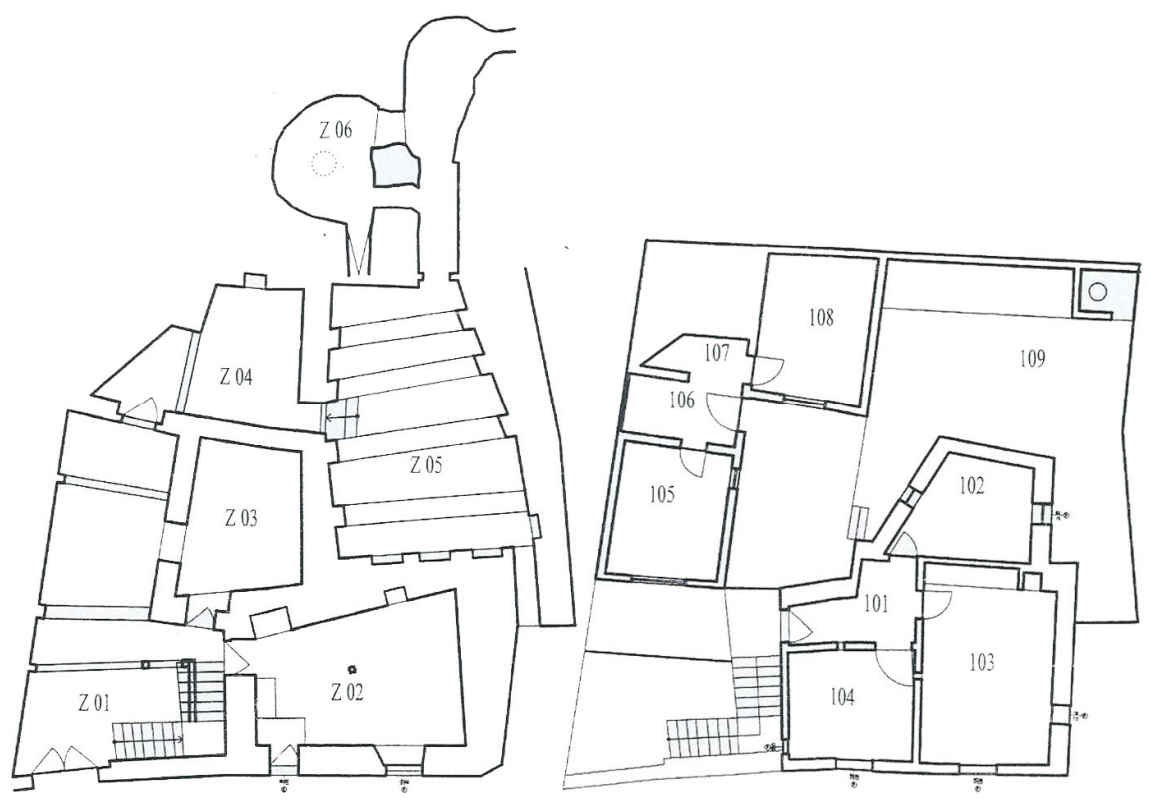

Figure 4: Ground and first floor plans of the Bahri Ozkan house. 


\subsubsection{Interior space organization}

It is entered the private properties through the street-doors connecting the streets and the courtyards. Once it is entered the courtyard, then it is directly reached to the floor furnace house and service spaces in the ground floor and basements. It is gone upstairs through the staircase in the courtyard.There is a space arrangement upstairs, which enables the dwelling of different nuclear families. The staircase arrives upstairs to a semi-open space called 'sallık', where there are direct entrances to the dwelling units of the nuclear families. From 'sallik' it is entered the 'sofa' of a unit. And from 'sofa' it is entered the rooms. These unites also include kitchen and bathroom.

\subsubsection{Pigeon loft, linseed oil terminal and watermill}

These are the building typologies specific to Ağırnas. They were specialized to be benefited from the diverse natural resources of the region. The rocks were carved for piegons to perch and to obtain fertilizer. The linseed oil production from the local plants was made in Ağırnas since $16^{\text {th }}$ Century in 28 different terminals and used for many purposes like cooking oil, fuel-oil, medication, etc (Akbas [8]). And the flour was obtained in the watermills by grinding the wheat. Unfortunately, none of the buildings are in use today.

\section{Disconnection}

The 1950s in Turkey are considered by many social scientists as a period of social transformation Karpat [9]. Industrialization, closure of 'village institutes', and high-immigration-rate from village to the city have been resulted in the change in the social and economic character of the country and vice versa. A $\breve{g} 1$ rnas is one of the tens of towns in Anatolia, which experienced this rapid change and couldn't sustain its living and building culture. People gave up teaching their children and grandchildren the way they live and built, because they were useless in the new economic system and in the new housing typology "apartment block", which is introduced and imposed by current politics and mass media. The new economic system was asking for workers working at big enterprices as a part of a huge system and the new housing typology was suitable to work at these big enterprices in the city and suitable for nuclear families newly emerged in the society. It doesn't require also much maintenance and seems like more comfortable than old vernacular houses. However, people started to live without knowing and respecting their neighbors, and forgot the knowledge of vernacular building techniques. And so, a disconnection in living and building culture generally in the whole Anatolia has been observed.

\section{A ğırnas today}

\subsection{Change in the socio-cultural values}

The differences in the values between the past and today of Ağırnas, which are referring in this paper to the mid- $20^{\text {th }}$ and early $21^{\text {st }}$ century, are shaped by the 
social transformations experienced in Turkey. As a part of the country, Ağırnas is also affected from these experiences of transformation and migration. Under new circumstances, the already existing ways of earning a living started to be insufficient in the region. The inability to provide new alternatives to be able to handle these new conditions resulted in the immigration of young burghers to the city and finding new jobs in new sectors. Following that, the sector of stockbreeding lost its significance. Handicrafts were no more transferred to next generations and jobs such as stonemasonry, which constitutes the spirit of the place, were forgotten in time. In the meantime, people started to live as nuclear families in apartments in the city, and the number of extended families was rapidly decreased. Thus, it can be deduced that the dominant family structure changed fundamentally. The towns became more and more deserted and the cultural wealth was lost because of these transformations. Human relations were also affected from that individualisation, and the socio-cultural values of the Anatolian people, such as collaboration and good relations with the neighbourhood vanished to a great extent. As a consequence of all these losses, the lifestyle habits of people altered entirely.

\subsection{Change in the architectural values}

Up until the 1950s, the protected area in Ağırnas, where the old stone houses are located, was perceived as the main residential area. It is even determined today that in the earthquake that took place in the first half of the $20^{\text {th }}$ century, the buildings were repaired and the single-storey-buildings became two-storey through the use of local hummer-dressed rubble stones. However, with the changes in the socio-cultural structure after 1950s, which are mentioned above, this continuity in the building customs ceased to exist. The stonemasonry has become extinct, and the processes of repairing houses become more and more difficult. And these deficiencies caused people to repair their houses on their own by using inappropriate techniques and unhealthy mass-produced materials. In addition to the lost stonemasonry practice, another change was seen in the architectural practice, which was the implementation of mass housing projects by the governmental agency "TOKI" (Housing Development Administration of Turkey). These houses are most often called TOKI Houses. They provide cheap accommodation, but they do not have an identity and has made designs regardless of their context and without paying attention to the ecological and cultural values. In the TOKI Houses, neither the natural values such as climate, topography and viewpoint; nor the built environment values such as direction, urban texture and street-square relations were taken into consideration. Thus, the richness of the scenarios for the public space usage has not been sustained. According to the information obtained from the mayor of Ağırnas, the place of old stone quarry has been determined as a new residential zone, and new TOKI Houses are going to built there (Mete [10]). Furthermore, according to the statement of an urban planner working in the municipality, the inhabitants of Ağırnas are also willing to move from these TOKI Houses and leave their old stone houses (Özçelik [11]). The sustainable architecture, which is advocated in this paper, will be possible only by a sustainable living style and a sustainable society. For sure, in a world, 
where change is a must, it is meaningless to look for living cultures and lifestyles the same with those of 100 years ago. However, it's necessary to interpret the principles of vernacular living and building culture and to reconstruct new principles and new design parameters for the changing conditions (Bektaş [12]).

\section{Conclusion}

\subsection{Proposals for current building practices}

First proposal to be regarded as a reference for current building practices in the region is about the direction and location of the building or building groups. In semi-arid and sub humid climates, locating the buildings in the south facing slope of a hill should be considered as a principle, as it is seen as such in vernacular stone buildings. When the main living space of a house faces the south, it receives the natural light which is necessary and the first condition for a healthy living. In addition, when the buildings are located on a hill, they do not obstruct the natural light, air, and view. Second principal for current building practices in the region is the proper arrangement of the streets from public to private, and changing the functions of the buildings around them. While the livelier and wider streets or even squares are surrounded by more functions and serve as a gathering place for community dwellers; more silent and narrower streets are surrounded by houses. Here, it's important to underline that activities taking place in the public streets and squares do not necessarily require spending money. They offer places for women to do cleaning and have conversations with friends, and for children to play. Low-rise, high-density housing model with a courtyard seen in the old settlement in Ağırnas is the third reference, which should be at the centre of attention for new constructions. With a careful design, low-rise settlements can be as dense as high-rise ones. The old town of Ağırnas is a proof for that. Today, what is challenging is acquiring the same density for new family structures, which mostly consist of 3-4 members in Turkey. Furthermore, the courtyard is the answer to the question of what the Anatolian culture and climate asks for. It provides shaded and non-shaded spaces at the same time during the day, and this satisfies the optimum thermal comfort conditions. It also provides open and semiopen spaces for the household, who have the tradition to use these spaces in their houses for ages for a variety of purposes. The fourth reference from the old town of Ağırnas should be the housing design, having the potential to be enlarged in case of necessity. The houses were enlarged in Anatolia, when the son of the family got married, as they were usually living together with their families. This was also typical in Ağırnas. A modular housing structure, enabling enlargement for new babies or new family members, is also very useful for today's building practices. It encourages people not to buy more than they need and also enable them to continue to live in the same house long enough to construct an identity and a sense of belonging to the place. Fifthly, the old town Ağırnas also serves as a reference for the shells of the buildings to be constructed. The thick stone walls and flat earthen roofs of vernacular buildings provide the most suitable conditions for the region's climate. It is the characteristics and qualifications of these 
materials, which should be perceived as a guideline for today's practices. The same materials should not necessarily be re-implemented. Yet, if there is going to be a change in the building materials, these new materials should offer either equal or better conditions (Bektaş [13]). Otherwise, using less-qualified materials than the ones produced almost a century ago cannot be accepted, only because they are easy to produce - and maintain.

\subsection{Proposals for further research and study in the other fields}

Repairing the human relations is more important than repairing the buildings. In the first years of the Turkish Republic, a person could not have a house which is higher than his/her neighbour's house. Seeing the private garden or the interior of the house of a neighbour was totally unacceptable and impolite (Bektaş [13]). Arrangements of the building practices in Anatolia were governed by people's prudence instead of rules prepared by the authorities. It sounds a little naive today but we should start from somewhere. To do so, firstly, the students in architecture departments should be educated properly and informed about the lifestyle and culture in Anatolia. Furthermore, there should be mediums, which gather the old and young citizens together, and enable their interaction within the framework of the lifestyle and culture. Otherwise, the disconnection mentioned in this paper can never be fixed. Secondly, lost and forgotten building techniques and materials should be re-studied and re-investigated. In Anatolia, the non-Muslim citizens worked in the relevant sectors, which required continuity in the Ottoman period, because the Muslim males were sent to fight in the wars. This resulted in the recruitment of the non-Muslim people in the building industry, as well. On the other hand, by the emigration of the non-Muslim society, an important part of the building culture and knowledge is lost (Bektaş [13]). In addition to that, it was also the cheap and quick mass production of building materials, which led people not to use the local and low-embodied energy materials. Whatever the reasons behind the lost knowledge are, there should be a nationwide effort and attempt to study and do research on them. Architect Sinan found the limestone, when he needed a light and rigid stone to construct a dome (Bektaş [13]). Thus, academicians and practitioners should also seek for new materials and techniques. Thirdly, the repair and restoration of the old stone buildings are among the important proposals of this paper. The buildings here do not refer only to the residential buildings of Ağırnas. There are unique typologies like linseed oil terminal, pigeon loft, and watermill, as well. Yet, none of these are in use today. However, they offer a great potential for a more sustainable life in Ağırnas. Despite the fact that these specialized buildings are left to decay, the houses are still being repaired by their occupants in order to sustain a living there. However, these repairing activities are realized without any guidance or help of professionals. There is a need for architects and engineers working in the municipalities to guide the house owners for more reasonable repair solutions. Finally, earning enough money to make a living is another vital condition for sustaining the life in Ağırnas. Being engaged in agriculture and stockbreeding under the 1950 s circumstances do not meet families' needs anymore. In addition, these families have more of necessities today and need to consume more, 
compared to the majority of the country in the 1950s. The perception of "enough money to make a living" is increasing in value each passing day, as a consequence of the government policies and global economic trends. Thus, firstly, the awareness of the burghers, as consumers, should be raised. When the Anatolians harvest their products, they set very little money aside to make a living and use the rest of the money to buy seeds or to give their sons in marriage preparations (Bektaş [13]). But today, we are almost in competition with one another to consume more. It's this perception, which should firstly be broken. And secondly, new ways of financial gain opportunities and potentials in Ağırnas should be researched. Without eliminating the first reason of migration, sustaining a healthy life in the town would not be possible.

\section{References}

[1] Ciravoğlu, A., Sürdürülebilirlik Düşüncesi-Mimarlı Etkileşimine Alternatif Bir Bakuş: Yer'in Çevre Bilincine Etkisi, YTU, İstanbul, 2006.

[2] Gould, K., Women in Green: Voice of Sustainable Design, Ecotone Publishing Company, Canada, 2007.

[3] Naes, A., Deep Ecology and Ultimate Premises, The Ecologist 18/4-5, pp. 128-131, 1988.

[4] Guy, S., Farmer, G., Reinterpreting Sustainable Architecture: The Place of Technology, Journal of Architectural Education, 54(3), pp. 140-148, 2001.

[5] Güzer, A., Dört Kişiydiler Bir de O (Chapter 5). Cengiz Bektaş, ed. Togay, N., Boyut Matbaacilık, İstanbul, pp. 55-61, 2001.

[6] Bektaş, C., Doğaya Uyumlu Mimarlı, Arkeoloji ve Sanat Yayınları, İstanbul, 2012.

[7] Okyay, A.G., Ağırnas Kentsel Sit Alanı ve Mimar Sinan Caddesi Üzerine Bir Araştırma, Yıldız Teknik Üniversitesi, İstanbul, 2007.

[8] Akbas, S.B., Kayseri Ansiklopedisi Cilt 1, Acar Basım, Istanbul, 2009.

[9] Karpat, K., Türkiye'de Toplumsal Dönüşüm, İmge Kitabevi, İstanbul, 2003.

[10] Mete, İ., Personal Communication, 15 April 2013, Mayor, Kayseri, Turkey.

[11] Özçelik, M., Personal Communication, 14 April 2013, Ağırnas Municipality Officer, Kayseri, Turkey.

[12] Bektaş, C., Yaşama Kültürü, Tasarım Yayın Grubu, İstanbul, 1996.

[13] Bektaş, C., Personal Communication, 30 April 2014, Head of Cengiz Bektaş İşliği, İstanbul, Turkey. 